\title{
Prevalence and correlates of drug use disorders in Mexico
}

\author{
María Elena Medina-Mora, ${ }^{1}$ Guilherme Borges, ${ }^{2}$ Clara Fleiz, ${ }^{1}$ \\ Corina Benjet, ${ }^{1}$ Estela Rojas, ${ }^{1}$ Joaquín Zambrano, ${ }^{1}$ \\ Jorge Villatoro, ${ }^{1}$ and Sergio Aguilar-Gaxiola ${ }^{3}$
}

Suggested citation Medina-Mora ME, Borges G, Fleiz C, Benjet C, Rojas E, Zambrano J, Villatoro J, Aguilar-Gaxiola S. Prevalence and correlates of drug use disorders in Mexico. Rev Panam Salud Publica. 2006;19(4): 265-76.

ABSTRACT Objective. To describe the prevalence of drug use disorders, the correlates of drug use, and the utilization of specialized treatment services for drug users among the Mexican urban population 18-65 years old.

Methods. The data were collected in 2001 and 2002 in the Mexican National Comorbidity Survey. The sample design was stratified probabilistically for six geographical areas of the country in a multistage process for census count areas, city blocks, groups of households, and individuals. The data were weighted, taking into account the probability of selection and the response rate. The information was collected using a computerized version of the World Mental Health Survey edition of the Composite International Diagnostic Interview. The weighted response rate for individuals was $76.6 \%$.

Results. Overall, $2.3 \%$ of the population reported any illicit use of drugs in the preceding 12 months; marijuana and cocaine were the substances most often used. Low levels of education were significantly associated with use, abuse, and dependence. Use of any drug was significantly more common among those who were in the youngest age group (18-29 years), were male, or were living in the Northwest region of the country. Overall, $1.4 \%$ had a lifetime history of drug abuse or dependence, with this being much more common for men (2.9\%) than for women $(0.2 \%)$. The 12-month prevalence of drug abuse or dependence was $0.4 \%$ overall $(0.9 \%$ for men, and $0.0 \%$ for women). The rate of treatment during the preceding 12 months for those with the 12-month criteria for abuse or dependence was $17.1 \% ; 14.8 \%$ were seen in specialized treatment centers; $2.8 \%$ reported having attended self-help groups.

Conclusions. A noticeable number of Mexicans have a drug use disorder, but demand for treatment is limited, in part due to stigma. Our results indicate that there is an urgent need to organize the specialized services for persons with a substance abuse disorder according to the prevalence of dependence on different substances and the variation in prevalence in the different regions of the country.

Key words Substance-related disorders; behavior, addictive; mental health services; health services needs and demand; Mexico.

1 Ramón de la Fuente National Institute of Psychiatry, Mexico City, Mexico. Send correspondence to: María Elena Medina-Mora, Investigación Epidemiológica y Psicosocial, Instituto Nacional de Psiquiatría Ramón de la Fuente, Calzada México Xochimilco 101, México, D.F., 14370, México; telephone: 52-55-56-55-42-68; fax: 55-13-34-46; e-mail: medinam@imp.edu.mx
2 Metropolitan Autonomous University, Xochimilco Campus, Mexico City, Mexico, and Ramón de la Fuente National Institute of Psychiatry, Mexico City, Mexico.

3 California State University, Fresno, Fresno, California, United States of America.
This report presents data on the lifetime and 12-month prevalence of drug use disorders and the demographic correlates of those disorders as found in the Mexican National Comorbidity Survey (M-NCS), which was conducted 
in 2001-2002. The Survey was coordinated by the Ramón de la Fuente National Institute of Psychiatry (Instituto Nacional de Psiquiatría Ramón de la Fuente) in Mexico and supported by Mexico's Secretariat of Health (Secretaría de Salud) and the National Council for Science and Technology (Consejo Nacional de Ciencia y Tecnología). The M-NCS is part of the World Health Organization's World Mental Health Survey initiative (1), which aims to evaluate the prevalence of mental disorders in countries with different degrees of economic development, to determine the health care needs for mental disorders, and to guide public policy on mental health.

Mexico has a long tradition of epidemiological research in the area of substance addiction (2-6), whereas the development of surveys aimed at assessing the prevalence of psychiatric disorders has been slower $(7,8)$. The first household surveys of drug abuse were conducted in the 1970s (2), with persons between 14 and 65 years of age in selected cities. The first National Survey on Addictions (Encuesta $\mathrm{Na}$ cional de Adicciones) was conducted in 1988 (3), in the urban population 12 to 65 years of age. The National Survey on Addictions of 1993 (4) and the Survey of 1998 (5) included subsamples in the three main metropolitan areas of the country (Mexico City; Guadalajara, Jalisco; and Monterrey, Nuevo León) and in the three cities on the border with the United States of America where the highest rates of abuse had been documented (Tijuana, Baja California; Ciudad Juárez, Chihuahua; and Matamoros, Tamaulipas) (9). The last National Survey on Addictions was conducted in 2002, and it included rural populations for the first time (6). In this paper we will compare our findings on prevalence rates from the M-NCS (conducted in 2001 and 2002) with the rates found in the $2002 \mathrm{Na}$ tional Survey on Addictions (6).

The 2002 National Survey on Addictions showed low prevalence rates of drug use in Mexico, with it being under $4 \%$ for lifetime use of any drug, not including alcohol or nicotine. Marijuana was the main drug reported.
The areas of Mexico bordering on the United States showed the highest prevalence rates for drug use (9).

In Mexico the demand for drugs started to rise at the end of the 1980s and the beginning of the 1990s. Rates of cocaine use among the urban population in the 12 months prior to the administration of the various National Survey on Addictions studies increased from $0.18 \%$ in 1988 to $0.45 \%$ in 1998, and leveled off at $0.38 \%$ in 2002. Rates of marijuana use showed a small, nonsignificant decrease from $1.21 \%$ in 1988 to $1.03 \%$ in 1998 , and decreased further, to $0.61 \%$, in 2002 . Inhalant use dropped from $0.15 \%$ in 1998 to $0.09 \%$ in $2002(3,5,6)$. The reported rapid increase in cocaine use, followed by a small decrease at the beginning of the new millennium, is consistent with what has been reported in school surveys (10) and with statistics for treatment demand (11). Trends for the use of marijuana and inhalants are also consistent with results from other sources, such as school surveys and statistics for treatment demand, which show a decrease in rates of inhalant use and an increase in the rates of marijuana use $(10,11)$. There has also been an increase in the rates of use of amphetamine-type stimulants as well as an extension of the heroin problem from cities on the border with the United States to a few other areas of Mexico (11).

The National Survey on Addictions interview includes a scale of symptoms that indicates dependence, as defined by the International Classification of Diseases 10th Revision (ICD-10) (12). The estimated rate was $0.38 \%$ in 1998 (5) and $0.44 \%$ in 2002 (6).

The first survey assessing psychiatric disorders using a standardized interview to determine the presence of substance abuse and dependence was conducted in Mexico City in 1997, using the World Health Organization Composite International Diagnostic Interview (CIDI) Fresno version 1.1 (13). The rate of substance dependence was estimated at $0.7 \%$ (8).

This paper extends our prior knowledge of drug use or drug dependence disorders from specific populations in
Mexico to a nationally representative household sample. Our research used a fully structured psychiatric interview to determine the prevalence of the disorders, risk factors for the disorders, and the patterns of the utilization of services for substance abuse disorders in the general population. The new data that we have produced can be compared with data from other countries participating in the World Mental Health Survey initiative since all of the nations used a similar, standardized questionnaire.

Using data from the M-NCS, an earlier publication (14) reported on the prevalence of drug and alcohol abuse and dependence disorders as defined by the ICD-10, the differences among different geographical areas, and the sociodemographic correlates of substance abuse disorders (including alcohol and other drugs). This new paper provides analyses of illicit drug use (which includes both the use of illegal drugs and the use of legal, prescription drugs taken without a prescription). This is the first time that prevalence rates for drug abuse and dependence have been provided for a national sample in Mexico based on the use of a standardized instrument, as well as the rates of service needs for drug abuse problems and the utilization of those services.

\section{METHODS}

\section{Sample}

A general description of the Mexican National Comorbidity Survey (M-NCS) (called the Encuesta Nacional de Epidemiología Psiquiátrica in Spanish) was presented earlier (14). Briefly, the M-NCS was based on a stratified, multistage probability sample of noninstitutionalized persons aged 18 to 65 years of age living in urban areas of Mexico. Areas with more than 2500 inhabitants are considered urban, and about $75 \%$ of the Mexican population live in such areas. The fieldwork was conducted by Berumen and Associates, a well-known survey firm in Mexico, by lay interviewers who were 
extensively trained by professionals who had broad experience in supervising and conducting household surveys. Data collection took place from September 2001 through May 2002.

The sample was designed to provide information for Mexico as a whole and for six geographic areas of the country. The six areas were: (1) the three largest metropolitan areas of the country, (2) the Northwest, (3) the Northeast, (4) the Central West, (5) the Central East, and (6) the Southeast. The three largest metropolitan areas are Mexico City; Guadalajara, Jalisco; and Monterrey, Nuevo León. The Northwest includes the states of Baja California, Baja California Sur, Nayarit, Sinaloa, and Sonora. The Northeast consists of the states of Chihuahua, Coahuila, Durango, Nuevo León (excluding the city of Monterrey), San Luis Potosí, Tamaulipas, and Zacatecas. The Central West region includes the states of Aguascalientes, Colima, Guanajuato, Jalisco (excluding the city of Guadalajara), and Michoacán. The Central East region includes the states of Guerrero, Hidalgo, México (excluding the counties (municipios) that are part of the Mexico City Metropolitan Area), Morelos, Puebla, Querétaro, and Tlaxcala. The Southeast consists of the states of Campeche, Chiapas, Oaxaca, Quintana Roo, Tabasco, Veracruz, and Yucatán.

The primary selection units (PSUs) were the census count areas from Mexico's 1990 census. Similar to census tracts in the United States, these census count areas are cartographically defined and updated by the National Institute of Statistics, Geography, and Informatics (Instituto Nacional de Estadística, Geografía e Informática). The census count areas were updated by the National Institute in 1994 and further updated by Berumen and Associates in 2001. The census count areas typically range in population from 3000 to 4000 persons of all ages, in some 500 to 650 households. A total of 200 PSUs were selected, with probability proportional to population size in each of the regions. The secondary sampling units were city blocks, with five city blocks selected within each PSU, with probability proportional to the size of each secondary sampling unit within each selected PSU. In total, 1000 blocks were selected. All the households within the selected city blocks were listed, and compact segments of approximately 10 households were formed, from which one segment was selected with equal probability, and all the households within that segment were included. Finally, one respondent was randomly selected from among the eligible household members in each household. Eligible household members were defined as all the Spanish-speaking persons who normally ate, slept, prepared meals, and were housed in the household and who were between the ages of 18 and 65 .

The M-NCS had two phases. During the first phase (September 2001 through December 2001) 10377 households were visited. The first round of the fieldwork included up to four or five visits to obtain an interview, at both the household and individual level. From January 2002 through May 2002 a second phase was implemented in order to reduce the nonresponse rate from households in the sample and to obtain more completed individual interviews. For the second phase a systematic subsample of 28 of the 66 PSUs in the three largest metropolitan areas and 33 of the 134 PSUs in the rest of the country was revisited. The strategy was to complete up to 10 callbacks (including those already completed in the first round) for each nonresponding household and each nonresponding individual. No financial incentives were given to the persons interviewed during any phase of the survey. The fieldwork ended in May 2002, with a total of 5826 interviews being completed.

The response rate, both at the household level and the individual level, takes into consideration the complex survey design and the revisit process. The weighted response rate at the household level was $91.3 \%$, and the weighted response rate at the individual level was $76.6 \%$. The main reason for nonparticipation at the individual level was "absent at the moment" (14.0\% of listed individuals). Direct refusals were infrequent $(6.2 \%$ of listed individuals). Other reasons for non- participation included incomplete or delayed interviews that could not be completed during the time scheduled for the fieldwork.

Diagnostic assessment. The instrument used was the World Mental Health Survey version of the Composite International Diagnostic Interview (CIDI) $(15,16)$, a structured diagnostic interview, installed on a laptop computer and administered face to face. The CIDI provides ICD-10 diagnoses and Diagnostic and Statistical Manual of Mental Disorders, Fourth Edition (DSM$I V)$ diagnoses. This paper reports on the DSM-IV diagnoses for mental disorders. In addition to lifetime, 12month, and 30-day diagnoses, sections of the CIDI include information on demographics, employment, finances, marriage and children, social networks, family burden (illnesses experienced by family members and the impact of those illnesses on the respondents), chronic medical conditions, pharmacoepidemiology, disability, and type of services used for mental disorders. The services section asked about persons that the respondent consulted for each of the mental health disorders present in the 12 months before the interview, including psychiatrists; other mental health specialists, such as psychologists, counselors, psychotherapists, mental health nurses, or social workers in a mental health specialty setting; general medical practitioners; other medical doctors, such as cardiologists or gynecologists; human services workers, such as religious or spiritual advisors or social workers or counselors in any setting other than a specialty mental health setting; and alternative/ complementary medicine, including the Internet, self-help groups, any other healer (such as a herbalist, chiropractor, or spiritualist), or some other alternative therapy.

Adequate interrater reliability (17, $18)$, test-retest reliability (19), and validity $(20,21)$ of earlier CIDI versions have been documented $(22,23)$. The translation of the instrument into Spanish was carried out by an interna- 
tional expert panel that was convened by the World Health Organization (WHO). The panel members, who were mental health experts qualified as clinicians and researchers, were from Chile, Colombia, Mexico, Panama, Spain, and the United States (including Puerto Rico). The panel members met on four occasions during 2000. In this process the panel followed WHO recommendations, with back-translation of selected items and terms of the clinical sections. The panel worked on the disagreements between the backtranslation from Spanish to English and the original English version. The disagreements found in the backtranslation were resolved by consensus. The panel also produced a list of problematic translation terms and their agreed-upon translations into Spanish. Additional minor adaptations to the Mexican context were made by consensus among the Mexican researchers who were responsible for the M-NCS.

All 5826 of the M-NCS respondents were administered a short form (Part I) of the CIDI, and a selected subsample of 2362 were administered a long form (Part II) of the CIDI, which had a number of supplemental questions on risk factors and additional disorders such as personality disorders and premenstrual syndrome. The subsample receiving the long form consisted of all the respondents who screened positive for any disorder on Part I (619 unweighted persons), plus a probability subsample of other Part I respondents (1 743 unweighted persons). The data reported in this article are based on this subsample of 2362 persons.

Interviewers, interviewer training, and quality control. The first stage of M-NCS fieldwork was conducted by 34 interviewers from Berumen and Associates who were experienced in systematic data collection. In August 2001 the interviewers went through an initial five days of training provided by the Mexican research team from the Ramón de la Fuente National Institute of Psychiatry. Following the first month of fieldwork, field supervisors from the Institute of Psychiatry pro- vided an additional day of training in order to remedy weaknesses that had been seen in the field. Another day of retraining was provided by the field supervisors from the Institute of Psychiatry in January 2002, prior to the second phase of the fieldwork.

A number of quality assurance measures were taken, such as preparing field manuals, providing continuous feedback to the supervisors from the Institute of Psychiatry and to field managers from Berumen and Associates, and having the main researchers assess both the supervisors and the interviewers. Over the course of all the fieldwork the research team continuously monitored the proportion of respondents who endorsed screening items for the most prevalent disorders. Periodically, the mean number of screening items endorsed in the interviews of each interviewer was calculated in order to monitor the interviewers' individual performance. Finally, quality control programs from the SAS statistical software package were used to identify possible errors regarding the dating of events (onset and recency, age consistency, and first and last service utilization) as well as to detect missing information. Households with incorrect or missing information were revisited. This was necessary mainly during the first weeks of fieldwork.

\section{Analysis}

The data were weighted to adjust for differential probabilities of selection and nonresponse. Two sets of weights were developed for the survey. The first set of weights, which were for the total sample of 5826 persons, were calculated based on three factors. The first factor took into consideration the inverse probability of selecting a respondent from a given household. A second factor was based on the inverse probability of selecting a person in the second phase of the study. A third factor was the result of post-stratification so that the weighted distribution of sex, age, and the survey strata (geographical areas) in the survey matched the distribution in the total Mexican population in the target age group, based on the year 2000 census data for the country.

A subgroup of 2362 participants in the M-NCS completed a long form of the interview. Weights for this subsample considered first the set of weights described above, and then adjusted for the inverse of the probability of being selected for the long form. Selection into the long form was based on a complex probability estimate that was generated by the computer interviewing program and that took into consideration a positive answer to a series of screening symptoms for the disorders included in the interview. In addition, a subgroup of persons without symptoms was chosen. The subsample was then normalized, taking into account the probability of selection, to match the characteristics of the complete sample.

Using this complex sample design and weighting, estimates of standard errors for proportions (lifetime and 12month prevalence estimates for mental disorders) were obtained with the Taylor series linearization method, using SUDAAN software (24). Logistic regression analysis (25) was performed to study demographic correlates of mental disorders. Estimates of standard errors of the odds ratios (ORs) obtained from logistic regression coefficients were also obtained with SUDAAN, and 95\% confidence intervals (CIs) were adjusted for design effects.

\section{RESULTS}

We provide data for use, abuse, and dependence. Use was defined as having consumed the substance at least once. Abuse was defined according to $D S M-I V$ criteria, as a maladaptive pattern of substance use causing clinically significant impairment, as indicated by at least one of the following four symptoms: (1) continued use despite knowledge of the social, occupational, psychological, or physical problems that are caused or exacerbated by consumption; (2) persistent use in dangerous situations; (3) substance-related 
legal problems; and (4) persistent use despite interpersonal conflicts. Persons meeting the criteria for dependence were excluded from the classification of abuse. Dependence was defined, also according to DSM-IV criteria, as a maladaptive pattern of substance use causing clinically significant impairment, as indicated by at least three of the following seven attributes: (1) tolerance; (2) withdrawal symptoms; (3) consumption in larger amounts or over longer periods than intended; (4) persistent desire or unsuccessful attempts to cut down or control use; (5) spending a large amount of time in activities related to obtaining, taking, or recovering from the effects of the substance; (6) reduction in social, occupational, or recreational activities due to substance use; and (7) persistent use despite knowledge of social, psychological, or physical difficulties due to or exacerbated by use. The substances included were marijuana, cocaine, tranquilizers used without a medical prescription, and other substances, which were grouped as "other drugs."

Table 1 presents the basic demographic distribution of the subsample of the persons who responded to the long form of the interview. A slight majority $(54 \%)$ of the sample was female, and $40 \%$ was in the youngest age group (18-29 years). Just over twothirds $(68 \%)$ of the population had at most finished primary school education (6th grade), and only $12 \%$ had completed college. Two-thirds (67\%) of the sample was either married or cohabiting, and $58 \%$ of the sample was

TABLE 1. Sociodemographic distribution of the subsample of persons who responded to a long form of the interview, Mexican National Comorbidity Survey, 2001-2002

\begin{tabular}{lrr}
\hline & \multicolumn{2}{c}{ Weighted subsample } \\
\cline { 2 - 3 } & $\%$ & SE $^{\mathrm{a}}$ \\
\hline Sex & & \\
Male & 46.31 & 1.59 \\
Female & 53.69 & 1.59 \\
Age (yr) & & \\
18-29 & 40.49 & 1.37 \\
$30-44$ & 34.25 & 1.22 \\
$45-59$ & 19.75 & 0.90 \\
60-65 & 5.51 & 0.58 \\
Education & & \\
None/Primary (0-6 yr) & 67.86 & 1.59 \\
Secondary (7-12 yr) & 13.26 & 1.02 \\
Some university (13-15 yr) & 6.97 & 0.67 \\
University graduate (16 yr) & 11.90 & 0.97 \\
Marital status & & \\
Married/Cohabiting & 67.12 & 1.32 \\
Divorced/Separated/Widowed & 7.43 & 0.65 \\
Never married & 25.45 & 1.15 \\
Geographic region & & \\
Three major metropolitan areas & 27.86 & 1.30 \\
Northwest & 8.37 & 0.95 \\
Northeast & 14.71 & 1.44 \\
Central West & 12.48 & 1.27 \\
Central East & 16.83 & 1.19 \\
Southeast & 19.75 & 1.57 \\
\hline a SE = standard error. & & \\
& &
\end{tabular}

working at the time of the interview. These data are consistent with census data in terms of the proportion of subjects in each category, with the demographic characteristics of the people in the sample being the same as those for persons 18 to 65 years old living in urban areas (26).

\section{How many people use, abuse, or are dependent on drugs}

Table 2 shows the rates of lifetime and 12-month use of any substance, by sex and age. Of the adult urban population of Mexico, $10.4 \%$ of them (representing 5.2 million people in total) had

TABLE 2. Lifetime and 12-month use of any type of drug, by age and sex, according to Mexican National Comorbidity Survey, 2001-2002

\begin{tabular}{|c|c|c|c|c|c|c|c|c|c|c|c|c|}
\hline \multirow[b]{3}{*}{ Age group (yr) } & \multicolumn{4}{|c|}{ Males } & \multicolumn{4}{|c|}{ Females } & \multicolumn{4}{|c|}{ Total } \\
\hline & \multicolumn{2}{|c|}{ Lifetime } & \multicolumn{2}{|c|}{ 12-month } & \multicolumn{2}{|c|}{ Lifetime } & \multicolumn{2}{|c|}{ 12-month } & \multicolumn{2}{|c|}{ Lifetime } & \multicolumn{2}{|c|}{ 12-month } \\
\hline & $\%$ & $\mathrm{SE}^{\mathrm{a}}$ & $\%$ & $\mathrm{SE}$ & $\%$ & SE & $\%$ & SE & $\%$ & SE & $\%$ & SE \\
\hline $18-29$ & 25.0 & 2.6 & 6.4 & 1.3 & 5.5 & 1.0 & 2.2 & 0.7 & 14.7 & 1.3 & 4.2 & 0.8 \\
\hline $30-44$ & 14.4 & 2.2 & 1.5 & 0.5 & 3.0 & 0.8 & 0.5 & 0.3 & 8.4 & 1.0 & 1.0 & 0.3 \\
\hline $45-59$ & 12.5 & 2.8 & 2.0 & 1.0 & 1.8 & 0.7 & 0.8 & 0.4 & 6.6 & 1.3 & 1.3 & 0.6 \\
\hline $60-65$ & 10.5 & 4.8 & 0.0 & 0.0 & 0.6 & 0.6 & 0.0 & 0.0 & 4.5 & 2.0 & 0.0 & 0.0 \\
\hline Total & 18.2 & 1.3 & 3.5 & 0.6 & 3.6 & 0.5 & 1.2 & 0.3 & 10.4 & 0.6 & 2.3 & 0.3 \\
\hline
\end{tabular}

\footnotetext{
a $\mathrm{SE}=$ standard error.
} 
TABLE 3. Lifetime and 12-month drug use, by type of drug and sex, according to Mexican National Comorbidity Survey, 2001-2002

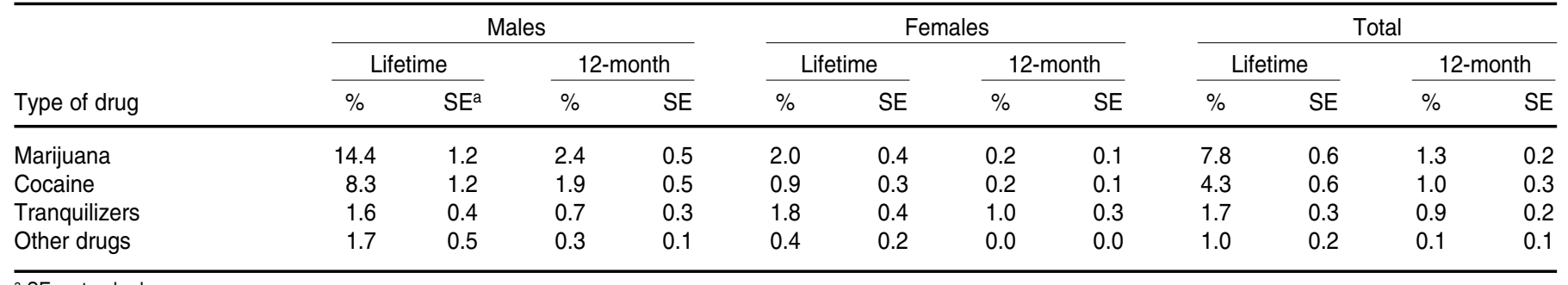

a $\mathrm{SE}=$ standard error.

used illicit substances at some point in their lifetime, with the rate for males being about five times the rate for females. The prevalence for the preceding 12 months was $2.3 \%$ overall $(3.5 \%$ for males and $1.2 \%$ for females).

Rates were higher in the younger age groups. People aged 60 to 65 did not report having used any of the substances in our study in the preceding year. There was a very consistent relationship between gender and substance abuse. For all the adults, more males $(18.2 \%)$ had used in their lifetime than had females (3.6\%) (Table 2). For lifetime use the smallest male- female ratio, 4.5, was in the youngest age group (18-29 years old), and the largest ratio, 17.5, was among those 60 to 65 .

In general, younger persons were more likely to report use and to experience dependence. The rates of use among males aged 18 to 29 was $25.0 \%$ for lifetime use and $6.4 \%$ for use in the last 12 months (Table 2). There was a sharp decrease in the rates of use for the next age group (30-44 years), with male lifetime use being $14.4 \%$, and use in the preceding 12 months being $1.5 \%$.

Table 3 shows the rates of use for different substances by sex. For males, marijuana (14.4\%) was the substance most frequently used in their lifetime, followed by cocaine $(8.3 \%)$. The drug of choice for females was also marijuana (2.0\% lifetime use), closely followed by tranquilizers (1.8\%). The rate of lifetime use of tranquilizers among females was slightly higher than among males.

Table 4 shows the rates of abuse and of dependence by sex and age groups. Overall, $1.4 \%$ of the population met the criteria for lifetime abuse or dependence, and $0.4 \%$ for the preceding 12 months. The diagnosis of lifetime abuse or dependence was 14.5 times

TABLE 4. Lifetime and 12-month drug abuse, dependence, and abuse or dependence, by age and gender, according to Mexican National Comorbidity Survey, 2001-2002

\begin{tabular}{|c|c|c|c|c|c|c|c|c|c|c|c|c|}
\hline \multirow[b]{3}{*}{ Gender and age } & \multicolumn{4}{|c|}{ Abuse } & \multicolumn{4}{|c|}{ Dependence } & \multicolumn{4}{|c|}{ Abuse or dependence } \\
\hline & \multicolumn{2}{|c|}{ Lifetime } & \multicolumn{2}{|c|}{ 12-month } & \multicolumn{2}{|c|}{ Lifetime } & \multicolumn{2}{|c|}{ 12-month } & \multicolumn{2}{|c|}{ Lifetime } & \multicolumn{2}{|c|}{ 12-month } \\
\hline & $\%$ & $\mathrm{SE}^{\mathrm{a}}$ & $\%$ & SE & $\%$ & $\mathrm{SE}$ & $\%$ & SE & $\%$ & SE & $\%$ & SE \\
\hline \multicolumn{13}{|l|}{ Males/Age (yr) } \\
\hline $18-29$ & 3.0 & 0.9 & 1.6 & 0.8 & 1.3 & 0.5 & 0.5 & 0.3 & 4.3 & 1.0 & 1.9 & 0.8 \\
\hline $30-44$ & 2.2 & 0.6 & 0.3 & 0.3 & 0.2 & 0.1 & 0.1 & 0.1 & 2.4 & 0.6 & 0.4 & 0.3 \\
\hline $45-59$ & 1.1 & 0.6 & 0.0 & 0.0 & 0.5 & 0.5 & 0.0 & 0.0 & 1.6 & 0.5 & 0.0 & 0.0 \\
\hline \multicolumn{13}{|l|}{ Females/Age (yr) } \\
\hline $18-29$ & 0.0 & 0.0 & 0.0 & 0.0 & 0.3 & 0.2 & 0.0 & 0.0 & 0.3 & 0.2 & 0.0 & 0.0 \\
\hline $30-44$ & 0.1 & 0.1 & 0.0 & 0.0 & 0.1 & 0.1 & 0.0 & 0.0 & 0.1 & 0.1 & 0.0 & 0.0 \\
\hline $45-59$ & 0.0 & 0.0 & 0.0 & 0.0 & 0.0 & 0.0 & 0.0 & 0.0 & 0.0 & 0.0 & 0.0 & 0.0 \\
\hline $60-65$ & 0.0 & 0.0 & 0.0 & 0.0 & 0.0 & 0.0 & 0.0 & 0.0 & 0.0 & 0.0 & 0.0 & 0.0 \\
\hline Total & 0.0 & 0.0 & 0.0 & 0.0 & 0.1 & 0.1 & 0.0 & 0.0 & 0.2 & 0.1 & 0.0 & 0.0 \\
\hline \multicolumn{13}{|c|}{ Males and females/Age (yr) } \\
\hline $60-65$ & 0.0 & 0.0 & 0.0 & 0.0 & 0.0 & 0.0 & 0.0 & 0.0 & 0.0 & 0.0 & 0.0 & 0.0 \\
\hline Total & 1.0 & 0.2 & 0.4 & 0.2 & 0.4 & 0.1 & 0.1 & 0.1 & 1.4 & 0.2 & 0.4 & 0.2 \\
\hline
\end{tabular}


FIGURE 1. Prevalence of lifetime drug abuse or dependence in the regions of Mexico, according to the Mexican National Comorbidity Survey, 2001-2002

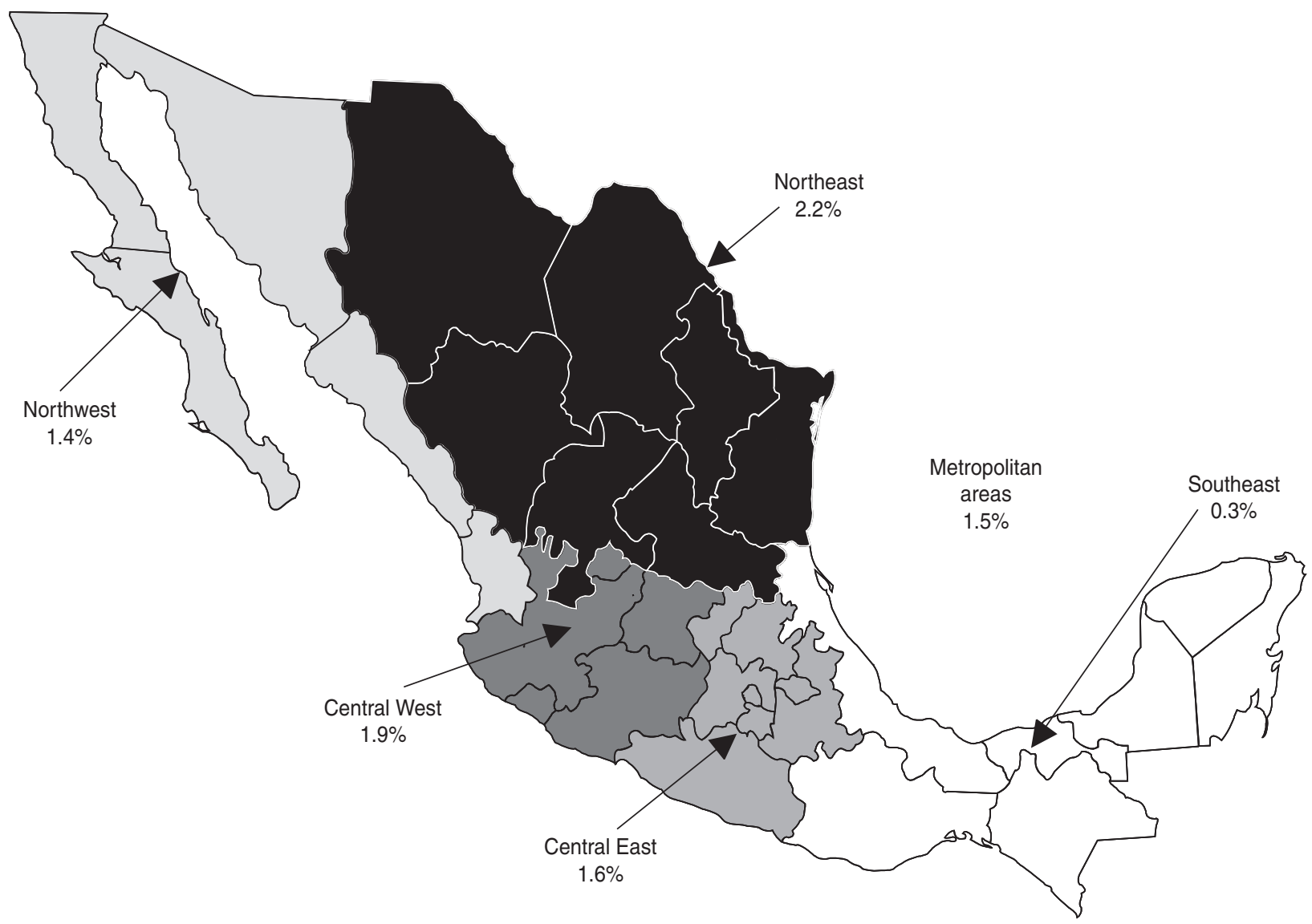

as frequent among males (2.9\%) as among females $(0.2 \%)$. The highest frequencies were seen in those 18-29 years old, while no cases of abuse or dependence were found among the population 60 to 65 .

Respondents who met the criteria for dependence during the preceding 12 months were classified by type of dependence, either with or without a physical dependence, as defined by withdrawal symptoms, tolerance, and difficulty controlling use. Around onefourth $(28.1 \%)$ of the persons with dependence were classified with physical dependence syndrome, and $71.9 \%$ were classified without that.

\section{Regional variations}

Regional variations in the prevalence of lifetime drug abuse or depen- dence are presented in Figure 1. The highest rates of lifetime drug abuse or dependence were reported in the Northeast region $(2.2 \%)$, followed by the Central West region $(1.9 \%)$. The population living in the Northwest region of the country, where the first drug epidemic was seen in the country and where for many years the highest rates of use were reported $(4,5,9,11)$, had a lifetime prevalence of abuse or dependence of $1.4 \%$. The lowest rate $(0.3 \%)$ was in the Southeast states.

Table 5 shows the odds of use and abuse or dependence according to the logistic regression analysis. Living in the Northwest region of the country was associated with a greater likelihood of ever using substances (OR = 1.68) and of having used in the preceding year $(\mathrm{OR}=2.11)$. The regional associations for abuse or dependence, however, did not follow the same pat- tern as for substance use. While the crude lifetime prevalence estimates of abuse or dependence shown in Figure 1 differed by region, the multiple logistic regression estimates shown in Table 5 suggested few differences. For example, the crude prevalence of abuse or dependence for the Northeast region was $2.2 \%$, and for the metropolitan areas it was 1.5.\% The unadjusted odds ratio (OR) was 1.48 (95\% confidence interval $(\mathrm{CI})=0.67-3.17)$ for the Northeast region (data not shown). When controls for sex, age, education, marital status, and employment were introduced, the adjusted OR for the Northeast region fell to 0.92 (95\% CI = 0.38-2.23) (Table 5). The only significant difference for lifetime abuse or dependence was the lower odds for the Southeast region $(\mathrm{OR}=0.16)$. Similarly, the likelihood of abuse or dependence in the previous 12 months 
TABLE 5. Sociodemographic correlates of lifetime and 12-month drug use, abuse, and dependence, according to Mexican National Comorbidity Survey, 2001-2002

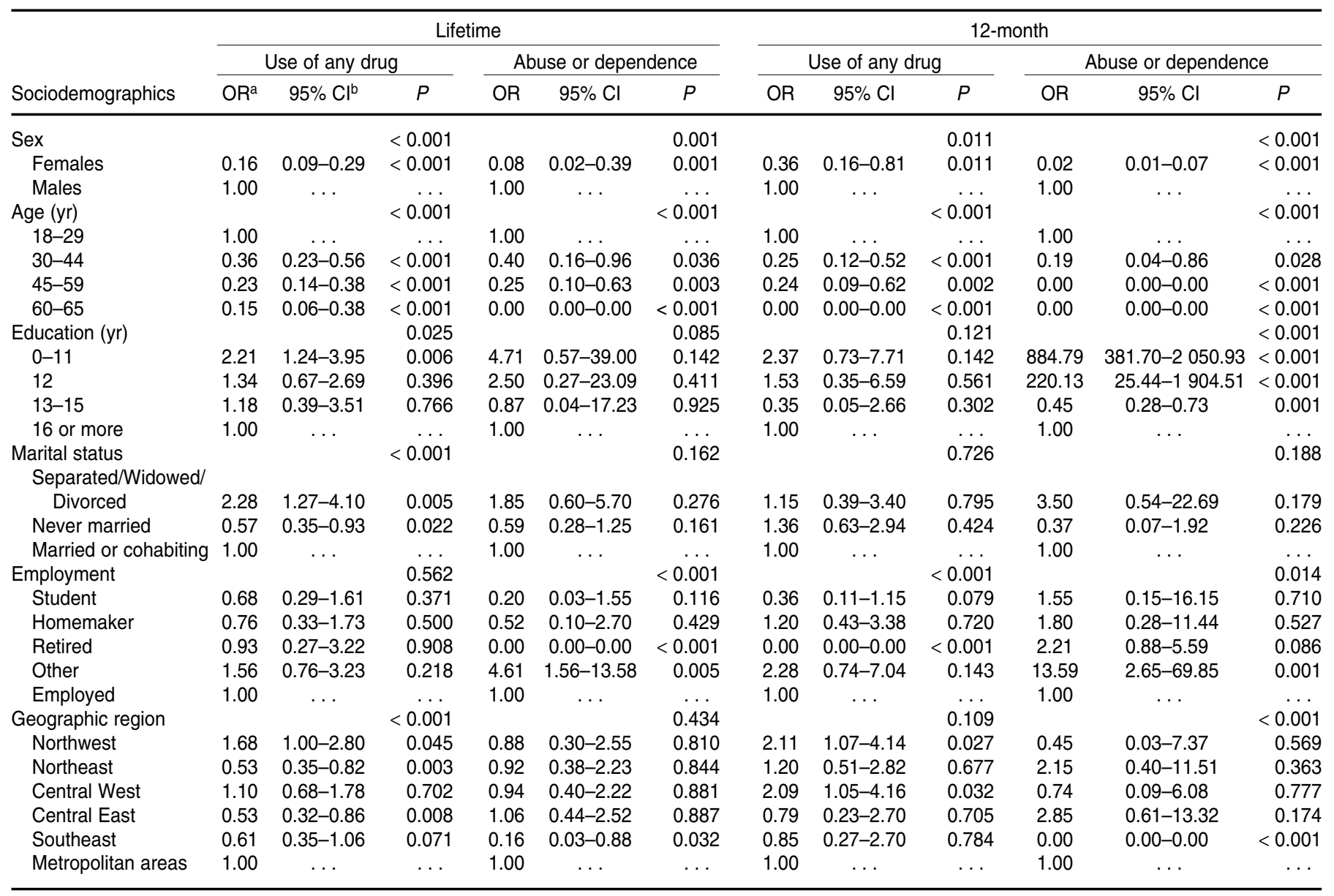

a $\mathrm{OR}=$ odds ratio. The ORs are from multiple logistic regressions that adjusted for sex, age, education, marital status, employment, and geographical region.

b $95 \% \mathrm{Cl}=95 \%$ confidence interval.

was significantly lower in the Southeast region $(\mathrm{OR}=0.0)$ than in metropolitan areas.

\section{Demographic correlates of disorder}

The likelihood of using drugs was significantly lower for females than for males, and also lower for those aged 30 or older than for those aged 18 to 29. As compared to those with 16 or more years of education, there was an association of low educational attainment (0-11 years of education) with lifetime illicit use of any drug $(\mathrm{OR}=$ 2.21). Being separated, widowed, or divorced significantly increased the likelihood of lifetime drug use as com- pared to those who were married or cohabiting $(\mathrm{OR}=2.28)$.

\section{Age of onset}

The median age of onset for lifetime drug dependence was early, around 17 years of age (not shown in the tables). For drug abusers the median age of onset of the disorder was 18 years. Figure 2 shows the survival curve for lifetime use by gender, and Figure 3 shows that information for lifetime drug abuse or dependence. Most first use and dependence was concentrated in the middle teens and early twenties; after the age of 30 years, new users of drugs were rare. Almost all cases were re- ported to have had onset before the age of 35 years. Both Figure 2 and Figure 3 show large gender differences in the prevalence of lifetime use and of lifetime abuse or dependence in Mexico.

\section{Treatment}

Treatment in the preceding 12 months was assessed by asking respondents if they had consulted any of a long list of professionals for problems with drugs, either as an outpatient or an inpatient, within the last 12 months. Included were mental health professionals (e.g., psychiatrists, psychologists), general medical professionals (e.g., general practition- 
FIGURE 2. Survival curves for lifetime drug use, by gender, according to the Mexican National Comorbidity Survey, 2001-2002

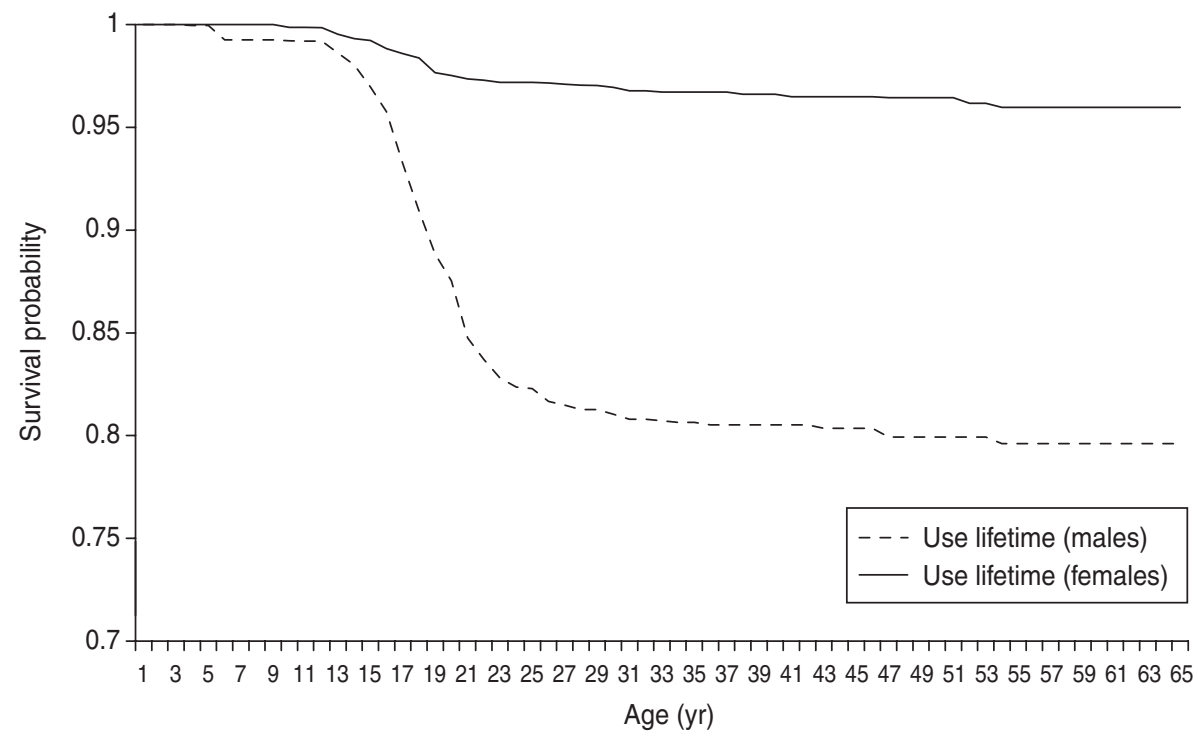

FIGURE 3. Survival curves for lifetime drug abuse or dependence, by gender, according to the Mexican National Comorbidity Survey, 2001-2002

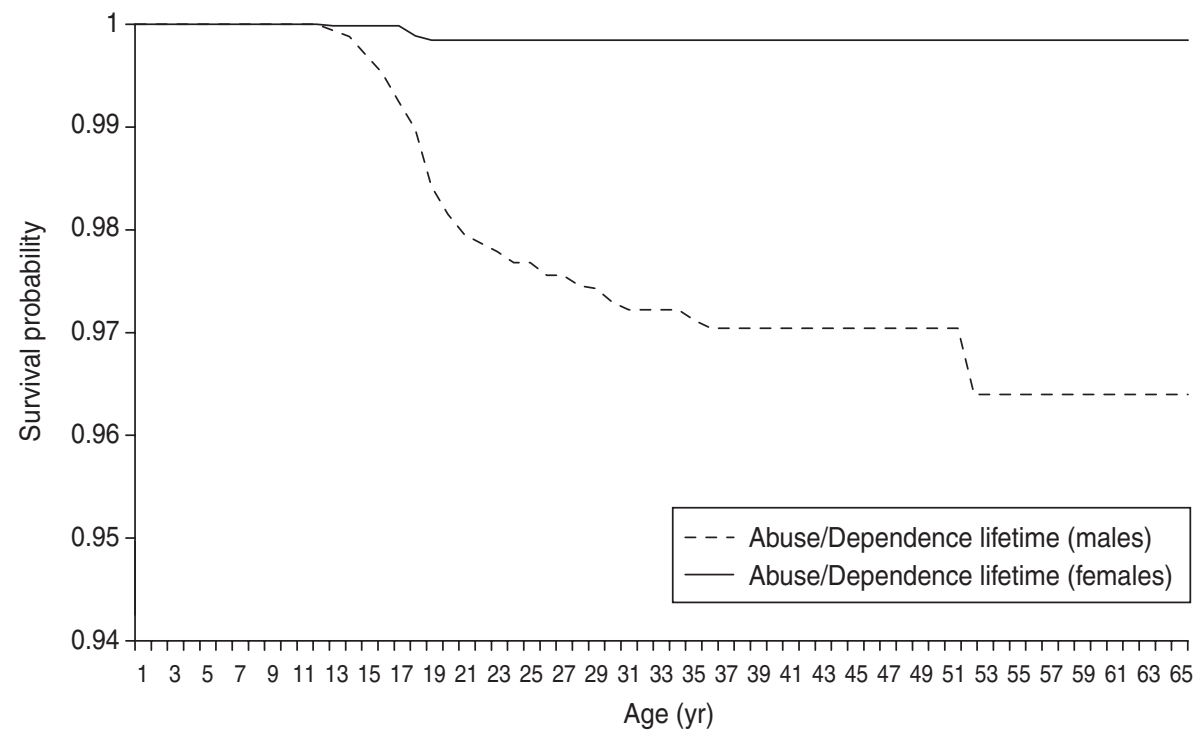

ers, occupational therapists), religious counselors (e.g., ministers), self-help groups, and traditional healers (e.g., herbalists, spiritualists).

Only a small proportion of persons with 12-month prevalence of abuse or dependence received treatment, with
$17.1 \%$ reporting receiving any health care treatment in the last 12 months (data not shown in tables). The most common sources of help were mental health specialists such as psychologists, counselors, psychotherapists, mental health nurses, and social work- ers in a mental health specialty setting $(14.8 \%)$. Psychiatrists $(8.2 \%)$ and general doctors $(2.8 \%)$ were seen by smaller proportions. Self-help groups $(2.8 \%)$ were not very commonly utilized by those dependent on drugs.

\section{DISCUSSION}

This study provided the first-ever national data for the adult urban population of Mexico on drug abuse and dependence and the proportion of persons with these disorders who had received treatment in the preceding 12 months. The survey response rate at the individual level was $76.6 \%$, well within the international norms for these complex surveys. Nonetheless, it is necessary to acknowledge that diagnosis was based solely on a single structured interview administered by a lay interviewer. Furthermore, while the reliability and validity of different versions of the CIDI are documented (19-23), studies have yet to evaluate the reliability and validity of all sections of the Spanish-language version. The prevalence rates and the age of onset presented in this paper are based on a retrospective self-report that is subject to recall bias and the willingness to disclose information truthfully. The M-NCS excluded adolescents under 17 years of age, whose rates of drug use are noticeable (27). In addition, the M-NCS did not include rural areas, where $24 \%$ of the population between 12 and 65 years of age and 16\% of the drug users reside, according to the 2002 National Survey on Addictions, which was conducted close in time to the M-NCS study (6). Homeless and institutionalized individuals, who have a higher prevalence of substance abuse disorders, were also excluded from the M-NCS (28). Nevertheless, due to the small numbers of institutionalized persons, it is not expected that this greatly influenced our estimates of lifetime and 12-month abuse or dependence. We consider our estimates to be minimum prevalences, which could have been higher if these excluded groups had been part of the sample. 


\section{Prevalence}

Our findings show that one in four males 18-29 years of age living in urban areas had used drugs in their lifetime, and that $6.4 \%$ of this group did so in the 12 months preceding the survey. Marijuana was the most common substance used, followed by cocaine. Recent-use and ever-use rates were considerably lower among persons 30 and older. Taken together, these data suggest that drug use is a phenomenon of the young, and that drug use has increased in the country in recent years. Consistent with the first onset of the drug abuse problem in Mexico in the late 1960s and early 1970s (9), these substance abuse disorders were not found among the population 60 to 65 years of age in the M-NCS. When drug use expanded in Mexico in the 1960s and the 1970s, the persons who are now over 60 years of age were then over the age of 25 and had thus already passed the age of major risk for drug use onset.

We found large differences between males and females, with drug use by males being much more common than among females. However, some data indicate that that difference is shrinking, with growing numbers of women using drugs (3). This trend has been shown in previous studies, most notably among adolescents (10). Despite the fact that more men than women use drugs overall, it is still more common for females to use prescription drugs illicitly, that is, without a doctor's authorization. This is especially true for tranquilizers. These data suggest the need to introduce a gender perspective in treatment programs.

Overall, only $0.4 \%$ of the urban population in our study met DSM-IV criteria for abuse or dependence during the preceding 12 months. This was very similar to the rates that have been reported for Mexico in the National Survey of Additions studies, such as the $0.38 \%$ for the urban population in 1998 (5) and the $0.44 \%$ for the urban and rural populations in 2002 (6). These rates are still much lower than what has been reported in the United States (29).

\section{Age of onset}

The M-NCS data on the age of onset in Mexico are in line with findings in other countries (30). In Mexico the onset of drug disorders begins around 17 years of age, while alcohol abuse or dependence and nicotine dependence tend to start around 25 years of age (14). The great majority of people who become dependent on drugs do so during late adolescence or in their early 20s. However, there are other periods of increased risk along the life span, such as between 25 and 30 years of age. There is also in a spike in the onset of abuse around age 52, but our sample size did not allow for a more detailed analysis of this. The late onset of abuse or dependence may be related to the illicit use of prescription drugs. This is suggested by the 2002 National Survey on Addictions, which found that $0.99 \%$ of those 35 to 65 years old were abusing tranquilizers, compared to $0.66 \%$ of those 18 to 35 years of age (6).

\section{Treatment}

Our data indicate extreme underutilization of treatment services. Only $17.1 \%$ of those with 12 -month abuse or dependence sought treatment in that same period. Contrary to what has been observed for alcohol disorders (31), only $2.8 \%$ of persons with 12 month drug abuse or dependence were enrolled in self-help groups. These low rates of treatment utilization contribute to increased severity as well as greater long-term impact, given the early age of onset of dependence.

The main components of the health system in Mexico are the Mexican Institute of Social Security (Instituto Mexicano del Seguro Social), which provides services for insured workers in the private sector; the State Workers' Social Security and Services Institute (Instituto de Seguridad y Servicios Sociales de los Trabajadores del Estado); and special services for other workers, such as those in the oil industry (PEMEX). These health services provide treatment for the complications of addictions (e.g., HIV) but not for the addictions themselves. In 2000, these institutions together provided services for only 39 million of the 100 million people living in Mexico, according to the National Institute of Statistics, Geography, and Informatics (26). The Government of Mexico is in the process of establishing a health insurance program for the most disadvantaged, but addictions will not be covered. Similarly, private insurance companies do not cover treatment for addictions. When it occurs, treatment for persons with these disorders takes place in specialized centers. Centers funded by the federal and state governments charge low fees, but using private centers often involves catastrophic out-of-pocket expenses.

For youth who have developed a drug use disorder, Mexico has a network of more than 90 specialized Government-funded treatment centers located around the country. These centers are operated by a civic group known as the Youth Integration Centers (Centros de Integración Juvenil). The Centers offer services at low fees, or free of charge for people who cannot afford to pay. Only two of the centers are residential ones. During 2002, 17978 persons were treated in these facilities. An additional 12370 persons were treated in that same year in the public sector (including services provided by union organizations and nongovernmental organizations), the private sector, and the social sector (11).

Residential services are scarce. Although there are 30000 beds available for those with an addiction, $60 \%$ of the beds are occupied by persons whose main addiction is alcohol. With the exception of residential services, the overall available capacity is greater than the demand (11). This suggests that stigma prevents those with serious addictions from seeking treatment.

The role that stigma might play in the small number of people seeking help is supported by findings coming from general population surveys. These studies have shown that the general public believes that addictions are both a disease and a vice. Further, it appears that the public do not understand that persons with an addic- 
tion require treatment to overcome the illness (32).

The data in this article suggest that a noticeable number of Mexicans have developed a drug disorder, but demand for treatment is limited. This limited demand is especially true among Mexicans with fewer years of schooling.

Our results indicate an urgent need to organize services for persons with drug use disorders according to the differences in the prevalence of dependence on the various substances, and the differences in prevalence by region. Our results also highlight the need to restructure the available treatment, to introduce a gender perspective into the treatment programs, to include programs that treat the drugs that are now consumed in the country, and to develop special strategies to increase the proportion of the affected population who utilize the services that are already available.

At present, addiction is not considered a disease that gives the affected persons the right to treatment. In order to ensure treatment for those affected, there is an urgent need to reorganize treatment services and integrate them with an adequate referral system. Community mobilization programs and educational initiatives aimed at informing people about the benefits of treatment and at reducing stigma could increase the proportion of people with substance abuse or dependence disorders who seek help.

Further studies are urgently needed to evaluate the reasons for this low proportion who seek help. An assessment of the referral systems within different levels of attention within the health system and in the workplace could provide valuable information on better ways to organize transfers for treatment. Gaining information on how people perceive their problems and possible ways to cope with abuse or dependence could guide programs aimed at informing the population about the disorders and strategies for overcoming them, including treatment. The role of stigma requires further studies aimed at understanding the mechanisms that prevent those who have developed an addiction from seeking treatment. Service providers need to be better able to identify those with abuse or dependence disorders and to refer them for adequate services in a timely manner. Studies assessing the costs related to addictions and the benefits from different interventions could help lead to in- creased public investments in the treatment of addictions.

Acknowledgments. Funding for this study came from the Ramón de la Fuente National Institute of Psychiatry grant 4280 and from the National Council on Science and Technology of Mexico grant G30544-H, with supplemental support from the Pan American Health Organization and the Pfizer Foundation, Mexico. The Mexican National Comorbidity Survey was carried out in conjunction with the World Health Organization World Mental Health (WMH) Survey Initiative. We thank the WMH staff for assistance with instrumentation, fieldwork, and data analysis. These activities were supported by the United States National Institute of Mental Health (grant R01MH070884), the John D. and Catherine T. MacArthur Foundation, the Pfizer Foundation, the United States Public Health Service (grants R13-MH066849, R01-MH069864, and R01 DA016558), the Fogarty International Center (FIRCA grant R01TW006481), the Pan American Health Organization, Eli Lilly and Company, Ortho-McNeil Pharmaceutical, GlaxoSmithKline, and Bristol-Myers Squibb.

\section{REFERENCES}

1. Kessler R, Aguilar S, Andrade L, Bijl R, Borges $\mathrm{G}$, Caraveo J, et al. Mental substance comorbidities in the ICPE surveys. Psychiatr Fennica. 2001;32(Suppl 2):62-79.

2. Medina-Mora ME. Prevalencia del consumo de drogas en algunas ciudades de la República Mexicana. Encuesta de hogares. Rev Ensen Invest Psicol. 1978;4(17):111-5.

3. Medina-Mora ME, Tapia CR, Sepúlveda J, Otero MR, Rascón ML, Solache G, et al. Extensión del consumo de drogas en México: Encuesta Nacional de Adicciones. Resultados nacionales. Salud Ment. 1989;12(2):7-12.

4. México, Secretaría de Salud, Dirección General de Epidemiología. Encuesta Nacional de Adicciones. México, D.F.: Secretaría de Salud; 1993.

5. México, Secretaría de Salud, Subsecretaría de Prevención y Control de Enfermedades, Instituto Mexicano de Psiquiatría, Dirección General de Epidemiología, Consejo Nacional contra las Adicciones. Encuesta Nacional de Adicciones. México, D.F.: Secretaría de Salud; 1998.
6. México, Secretaría de Salud, Consejo Nacional contra las Adicciones, Instituto Mexicano de Psiquiatría, Dirección General de Epidemiología. Encuesta Nacional de Adicciones. México, D.F.: Secretaría de Salud; 2002.

7. Berenzon S, Medina-Mora ME, López EK, González J. Prevalencia de trastornos mentales y variables asociadas en cuatro comunidades del sur de la ciudad de México. Rev Mex Psicol. 1998;15(2):177-85.

8. Caraveo AJ, Colmenares EB, Saldívar G. Morbilidad psiquiátrica en la ciudad de México: prevalencia y comorbilidad a lo largo de la vida. Salud Ment. 1999;22(número especial): 62-7.

9. Medina-Mora ME, Cravioto P, Ortiz A, Kuri P, Villatoro J. Mexico: systems for the epidemiological diagnosis of drug abuse. Bull Narc. 2003;55(1-2):105-9.

10. Villatoro J, Medina-Mora ME, Rojano CJ, Fleiz C, Bermúdez P, Castro P, et al. ¿Ha cambiado el consumo de drogas de los estudiantes? Resultados de la Encuesta de Estudiantes. Medición otoño del 2000. Salud Ment. 2002;25(1): $43-54$.
11. Tapia-Conyer R, Kuri P, Cravioto P, García E, Galván F, Fernández E, et al. Sistema de Vigilancia Epidemiológica de las Adicciones. In: Observatorio mexicano en tabaco, alcohol y otras drogas 2002. México, D.F.: Consejo Nacional Contra las Adicciones-Secretaría de Salud; 2002. Pp. 33-61.

12. Villatoro VJ, Medina-Mora ME, López LE, Juárez GF, Rivera GE, Fleiz BC. La dependencia y los problemas asociados al consumo de drogas en México. Resultados de la Encuesta Nacional de Adicciones. Salud Ment. 1996; 19(3):1-6.

13. Aguilar-Gaxiola S, Vega W, Peifer K, Gray T. Development of the Fresno Composite International Diagnostic Interview. Berkeley: University of California, Institute for Mental Health Services Research; 1995.

14. Medina-Mora ME, Borges G, Lara MC, Benjet C, Blanco J, Fleiz C, et al. Prevalencia de trastornos mentales y uso de servicios: resultados de la Encuesta Nacional de Epidemiología Psiquiátrica en México. Salud Ment. 2003; 26(4):1-16. 
15. Kessler R, Berglund PA, Walters EE, Leaf PJ, Kouzis AC, Bruce ML, et al. Population-based analyses: a methodology for estimating the 12-month prevalence of serious mental illness. In: Manderscheld RW, Henderson MJ, eds. Mental health. Washington, D.C.: Government Printing Office; 1998. Pp. 99-109.

16. World Health Organization. Composite International Diagnostic Interview. 15th version. Geneva: WHO; 2000.

17. Wittchen HU, Robins LN, Cottler LB, Sartorius N, Burke JD, Regier DA, et al. Crosscultural feasibility, reliability and sources of variance in the Composite International Diagnostic Interview (CIDI). Br J Psychiatry. 1991; 159:645-53.

18. Cottler LB, Robins LN, Grant BF, Blaine J, Towle LH, Wittchen HU, et al. The CIDI-core substance abuse and dependence questions: cross-cultural and nosological issues. Br J Psychiatry. 1991;159:653-8.

19. Wacker HR, Battegay R, Mullejans R, Schlosser C. Using the CIDI-C in the general population. In: Stefanis CN, Rabavilas AD, Soldatos CR, eds. Psychiatry: a world perspective. Amsterdam: Elsevier Science; 1990. Pp. 138-43.

20. Farmer AE, Katz R, McGuffin P, Bebbington PA. Comparison between the Present State Examination and the Composite International Diagnostic Interview. Arch Gen Psychiatry. 1987;44:1064-8.
21. Janca A, Robins LN, Cottler LB, Early TS. Clinical observation of CIDI assessments: an analysis of the CIDI Field Trials-Wave II at the St. Louis site. Br J Psychiatry. 1992;160: 815-8.

22. Andrews G, Peters L. The psychometric properties of the Composite International Diagnostic Interview. Soc Psychiatry Psychiatr Epidemiol. 1998;33:80-8.

23. Caraveo J, González C, Ramos L. The concurrent validity of the DIS: experience with psychiatric patients in Mexico City. Hispanic J Behav Sci. 1991;13:63-77.

24. Research Triangle Institute. SUDAAN. Release 8.0.1. Research Triangle Park: RTI; 2002.

25. Hosmer DW, Lemeshow S. Applied logistic regression. 2nd ed. New York: John Wiley \& Sons; 2000.

26. México, Instituto Nacional de Estadística, Geografía e Informática. Censo General de Población y Vivienda. México, D.F.: INEGI; 2000.

27. Medina-Mora ME, Cravioto P, Villatoro J, Fleiz C, Galván F, Tapia R. Consumo de drogas entre adolescentes. Resultados de la Encuesta Nacional de Adicciones, 1998. Salud Publica Mex. 2003;45 Suppl 1:16-25.

28. Cravioto P, Medina-Mora ME, De la Rosa B, Galván F, Tapia R. Patrones de consumo de heroína en una cárcel de la frontera norte de México: barreras de acceso a tratamiento. Salud Publica Mex. 2003;45(3):181-90.
29. United States, Substance Abuse and Mental Health Services Administration. Results from the 2001 National Household Survey on Drug Abuse. Rockville: SAMHSA; 2002.

30. Merikangas KR, Mehta RL, Molnar BE, Walters EE, Swendsen JD, Aguilar-Gaxiola SA, et al. Comorbidity of substance use disorders with mood and anxiety disorders: results of the International Consortium of Psychiatric Epidemiology. Addict Behav. 1998;23:893-907.

31. Rosovsky H, Leyva G. Movimiento de Alcohólicos Anónimos en México. In: Instituto Nacional de Psiquiatría "Ramón de la Fuente Muñíz," ed. Anales. Reseña de la V Reunión de Investigación. México, D.F.: Instituto Nacional de Psiquiatría "Ramón de la Fuente Muñíz"; 1990. Pp. 5-8.

32. Medina-Mora ME. Diferencias por género en las prácticas de consumo de alcohol. Resultados de un estudio llevado a cabo en la población de 18 años y más de una entidad urbana y otra rural del estado de Michoacán [Ph.D. thesis]. Universidad Autónoma de México; 1993.

Manuscript received 28 October 2004. Revised version accepted for publication 15 February 2006.
RESUMEN

Prevalencia de trastornos vinculados con el consumo de drogas y factores relacionados con ellos, en México

Palabras clave
Objetivo. Describir la prevalencia de tastornos relacionados con el consumo de drogas, sus factores asociados, y la utilización de servicios terapéuticos especializados por usuarios de drogas en la población urbana de México entre los 18 y 65 años de edad.

Métodos. Los datos se reunieron en 2001 y 2002 mediante la Encuesta Nacional de Epidemiologia Psiquiátrica de México. El muestreo se llevó a cabo por estratificación probabilística de seis regiones geográficas del país en un proceso polietápico que comprendió, en orden sucesivo, áreas censuales, manzanas urbanas, grupos de domicilios, e individuos. Los datos se ponderaron teniendo en cuenta la probabilidad de selección y el porcentaje de respuesta. La información se recogió mediante una versión computadorizada de la edición de la Entrevista Diagnóstica Internacional Compuesta usada para la Encuesta Mundial de Salud Mental. El porcentaje de respuesta ponderado para individuos fue de 76,6.

Resultados. En general, 2,3\% de la población declaró haber incurrido en el consumo ilícito de drogas durante los 12 meses anteriores a la encuesta; la marijuana y la cocaína fueron las sustancias consumidas con mayor frecuencia. La baja escolaridad mostró una asociación significativa con el consumo, el abuso y la dependencia de drogas. El consumo de cualquier tipo de droga tuvo una frecuencia significativamente mayor en personas pertenecientes al grupo de edad más joven (18-29 años), en varones, o en habitantes de la parte noroccidental del país. De la muestra en general, 1,4\% había abusado o dependido de las drogas en algún momento de la vida, y ello ocurrió con mucha más frecuencia en varones $(2,9 \%)$ que en mujeres $(0,2 \%)$. La prevalencia del abuso o de la dependencia de drogas en el transcurso de los 12 meses anteriores a la encuesta fue de $0,4 \%$ en general ( $0,9 \%$ en varones y $0,0 \%$ en mujeres). La tasa de tratamiento durante los 12 meses anteriores a la encuesta entre quienes cumplían los criterios de abuso o dependencia durante ese período fue de $17,1 \% ; 14,8 \%$ fueron atendidos en centros de tratamiento especializados, y 2,8\% dijeron haber asistido a grupos de autoayuda.

Conclusiones. Un número apreciable de mexicanos tienen un trastorno relacionado con el consumo de drogas, pero la demanda de un tratamiento es poca, en parte debido a temor al estigma. Según nuestros resultados, urge organizar los servicios especializados para personas con trastornos vinculados al abuso de sustancias en función de la prevalencia de la dependencia de las diversas sustancias y de la variación que muestra esta prevalencia en las distintas regiones del país.

Trastornos relacionados con sustancias, conducta adictiva, servicios de salud mental, necesidades y demanda de servicios de salud, México. 